\title{
PHYLOGENETIC DIVERSITY AS A KEY TO UNDERSTAND MECHANISMS OF NEW WORLD MARSUPIALS DIVERSIFICATION (DIDELPHIMORPHIA: DIDELPHIDAE)
}

\author{
Marcos de Souza Lima Figueiredo ${ }^{1,2 *}$ \& Carlos Eduardo de Viveiros Grelle ${ }^{1}$ \\ ${ }^{1}$ Universidade Federal do Rio de Janeiro, Instituto de Biologia, Departamento de Ecologia, Laboratório de \\ Vertebrados, CP 68020, Ilha do Fundão, CEP 21941-590, Rio de Janeiro, RJ, Brazil. \\ 2 Universidade Federal do Estado do Rio de Janeiro, Instituto de Biociências, Programa de Pós-Graduação em \\ Biodiversidade Neotropical, CEP 22290-240, Rio de Janeiro, RJ, Brazil. \\ E-mails: mslfigueiredo@gmail.com (*corresponding author); cevgrelle@gmail.com
}

\begin{abstract}
Phylogenetic diversity is a measure that can provide information about the history of diversification of a lineage and the events that shaped contemporary communities, as macroevolutionary processes leave marks on the relationships of the lineages. However, this approach has been applied primarily in studies on local scales, and rarely has been employed to analyze regional or continental patterns. Here we mapped spatial patterns that could identify regions of intense diversification or dispersion of the New World marsupials (order Didelphimorphia) by analyzing the spatial variation of species richness and phylogenetic diversity (PD). Based on the phylogeny and occurrences of the Didelphimorphia species we calculated three diversity measures, and applied a model selection by information criteria approach to identify the relative importance of four environmental determinants: potential evapotranspiration, productivity, topography, and the number of ecoregions. Species richness and PD are highly correlated, and both are associated to productivity, topography, and number of ecoregions, while relative $\mathrm{PD}$ (rPD) is associated to potential evapotranspiration and topography. Productivity showed a clear positive relation with species richness and PD, consistent with the productive energy, but rPD was affected by potential evapotranspiration, which points to a role of environmental energy in the process of diversification. This study is pioneer in testing and confirming effects of the productive and environmental energy on species diversification as other studies analyzing the same questions neither could isolate the effects of the two energy measurements due to their collinearity, nor did make any distinction between energy hypotheses. Physical geography and ecological differences among habitats can shape biogeographical patterns and drive speciation in continental faunas, leaving marks on their phylogenetic register. Comparing patterns among other autochthonous taxa whose evolutionary history and geographic range is congruent to the Didelphimorphia could provide interesting clues about the processes that shaped the diversification of Neotropical fauna.
\end{abstract}

Keywords: environmental energy; macroecology; productivity; spatial heterogeneity; topography. 


\section{INTRODUCTION}

The increase in species richness towards the tropics is one of the oldest and most general patterns in biogeography (Hawkins 2001) and has been recorded in virtually all major taxa in various geographic contexts or time periods (Willig et al. 2003). Due its generality, many hypotheses have been proposed to explain this pattern (Pianka 1966, Willig et al. 2003, Fine 2015), but most of them are flawed as the hypothesized mechanisms are either too specific to explain such a general pattern of diversity (Willig et al. 2003), or lack of empirical evidence or still due to circular reasoning (Rohde 1992). Nowadays, it is widely accepted that few factors are central in the generation and maintenance of this pattern (Willig et al. 2003, Fine 2015), among them energy (Hawkins et al. 2003a), habitat heterogeneity (Kerr \& Packer 1997), and higher tropical diversification (Mittelbach et al. 2007, Fine 2015). Despite the importance of these factors, usually a considerable part of variation is not explained in the models (Rahbek \& Graves 2001), and the unexplained variation is generally attributed to macroevolutionary processes, such as dispersion and diversification (Hawkins et al. 2003b), which leave marks on the phylogenetic relationships of the lineages (Fritz \& Rahbek 2012).

Phylogenetic diversity is a measure that can provide information about the history of diversification of a lineage (i.e., speciation minus extinctions), and the events that shaped contemporary communities (Webb 2000, Webb et al. 2002, Weiblen et al. 2006). For example, if the phylogenetic diversity of a community reflects the number of lineages it contains, then a species-rich community which exhibits a low phylogenetic diversity apparently results from a large radiation of a few lineages. This suggests that the diversity in this region has an autochthonous origin and that other lineages of the same taxon were not successful in colonizing it or were extinct before they could diversify. Likewise, if a species-rich region presents high phylogenetic diversity, this may be due to the presence of many different phylogenetic lineages, and it is possible that occurred the colonization of multiple lineages, followed by their diversification (Davies \& Buckley 2011, Fritz \& Rahbek 2012).
The emergence of new ways of measuring biological diversity, such as phylogenetic diversity, has shed light on known patterns and at the same time has raised new questions about its structuring mechanisms (Magurran 2004, Leibold et al. 2010). Unlike species richness patterns, which has been a central topic of ecology for many years (Hawkins 2001, Magurran 2004), patterns of phylogenetic diversity are largely unknown due the (until recently) unavailability of comprehensive phylogenies (Voskamp et al. 2017), but based on the mechanisms responsible for the hypotheses associated with species richness, it is possible to hypothesize the predominant diversification processes (Davies et al. 2007). However, this approach has been applied primarily in studies on local scales, and only recently it has been employed to analyze regional or continental patterns (Davies et al. 2007, Terribile et al. 2009, Kamilar \& Guidi 2010, Fritz \& Rahbek 2012, Fenker et al. 2014, Fergnani \& Ruggiero 2017, Voskamp et al. 2017). Most of these studies are aimed at describing patterns of spatial variation in diversity measures, and only two of them (Davies et al. 2007, Voskamp et al. 2017) made explicit predictions about the ecological and evolutionary mechanisms that may be acting in the origin and maintenance of the geographical patterns of phylogenetic diversity.

The energy hypothesis, which has been employed with great success in the analysis of diversity gradients, has two main strands: environmental energy and productive energy (Hawkins et al. 2003b, Brown 2014). Environmental energy (i.e., temperature and ultraviolet radiation) may affect mutation rates, and hence population speciation (Rohde 1992, Kaspari et al. 2004, Evans \& Gaston 2005) or may represent a physiological barrier, influencing extinction (Currie 1991). Productive energy (i.e., net productivity) in turn predicts that more productive areas support more individuals, and that larger populations are then less prone to extinction (Evans et al. 2005a, 2005b), resulting in greater local diversity due to accumulation of species in an area. In either strand, it is expected a positive relation between energy and species richness (Brown 2014), but the productive energy hypothesis can also result in a hump-shaped 
relationship depending on the spatial scale of the analysis (Mittelbach et al. 2001). Both energy hypotheses would predict a positive relationship to the phylogenetic diversity, but the mechanism underlying this increase is different for the two of them. The higher phylogenetic diversity associated to the environmental energy would be resultant of an increase in speciation rates, while the same pattern observed on the productive energy would be caused by reduced extinction of the lineages.

In addition to energy, environmental heterogeneity also has been used to explain diversity patterns (Kerr \& Packer 1997, Rahbek \& Graves 2001), being caused by factors, such as variation in topography, vegetation types, and vegetation structure over time (Davies et al. 2007, Melo et al. 2009). According to this hypothesis, greater heterogeneity at mesoscale would allow the coexistence of more species due to different environmental requirements and interactions with other species (Leibold 1998, Leibold et al. 2004), and may be the result of processes that operate on ecological or evolutionary time scales, thus having different consequences on the phylogeny of the species of a given area. Processes on evolutionary time scales (e.g., vicariance) are associated with an increase in the rates of speciation of a few lineages, thus having a negative relation with phylogenetic diversity. Those which operate on ecological time scales (e.g., niche partition), on the other hand, are associated to a positive but weak relation to phylogenetic diversity, as different habitats are mostly coincident with independent phylogenetic histories of their respective communities (Davies et al. 2007).

Here, our objective was to map spatial patterns that could identify regions of intense diversification or dispersion of the New World marsupials (order Didelphimorphia), by analyzing the spatial variation of the residuals of the relation between species richness and phylogenetic diversity. Due the fact that marsupials originated in the Upper Cretaceous, have diversified throughout the Miocene, and have colonized North America only in the Pliocene (Astúa 2015), the Didelphimorphia underwent several geological events such as the rise of the Andes and the Atlantic mountain ranges, and the formations of the tropical forests and open vegetation of South America (Costa 2003, Giarla \& Jansa 2014, Sobral-Souza \& Lima-Ribeiro 2017), and some of these events must have left a register in their phylogeny. We also analyze the relative importance of energy hypotheses and environmental heterogeneity on the spatial structuring of these diversity measures, in search of possible structuring mechanisms.

\section{MATERIAL AND METHODS}

\section{Data Collection}

Geographic distribution maps of Didelphimorphia species are available in digital format (IUCN 2012) compatible with ArcGIS 10. These maps were projected on a grid formed by hexagons of 12,100 $\mathrm{km}^{2}$ mounted on the American continent, and for each hexagon a list was produced with all occurrences of all 97 Didelphimorphia species. This grid was created using the equivalent cylindrical (Behrman) projection to avoid deformations in the represented area that could interfere in the diversity patterns. All hexagons with less than $50 \%$ of the area occupied by the continental surface were disregarded from the analysis in order to control the effects of area and island isolation on the diversity measures used. Based on these criteria, 3,098 hexagons were obtained on the surface of the American continent, of which 1,923 had at least one species of Didelphimorphia.

Information on the phylogeny of Didelphimorphia was extracted from a consensus tree based on 100 randomly sampled trees obtained on Faurby \& Svenning (2015). Species absent from the phylogeny but present in the list of species analyzed were included in the most basal node common to all genus. In the case of species added to monotypic genera, the genus was divided into two species and the division was established as half the length of the arm.

Based on the phylogeny and occurrences of the Didelphimorphia species, three measures of diversity were calculated for each hexagon: (i) species richness; (ii) the phylogenetic diversity (PD), estimated on the basis of the PD index (Faith 1992), which represents the sum of arm length in the portion of a phylogenetic tree containing all species in a given hexagon; and (iii) relative phylogenetic diversity (rPD), defined as the residue of the relation between phylogenetic 
diversity and species richness. This measure was calculated because the Faith's PD index is strongly influenced by species richness (Schweiger et al. 2008), and by removing its effect, the role of extinction and speciation processes on the diversification of a lineage tend to be evidenced (Davies et al. 2007, Fritz \& Rahbek 2012).

To analyze the effect of the environment on the diversity patterns, four variables were defined that represent different measures of energy or environmental heterogeneity. All variables were obtained from georeferenced databases available on the internet in an ArcGIS 10 compatible format and were redesigned to fit the hexagonal grid (see above). The four variables are: (i) potential evapotranspiration (PET), which represents the environmental energy hypothesis and was obtained from the Global Aridity and PET Database website (http://www.cgiar-csi.org/data/ global-aridity-and-pet-database); (ii) net primary productivity (NPP), which is a measure that represents the hypothesis of productive energy and was calculated from the sum of the monthly NPP maps on the NASA Earth Observatory System (http://neo.sci.gsfc.nasa.gov/Search.html); topography (Topo), which represents the topographic heterogeneity of a region and was calculated as the standard deviation of the altitude measurements [obtained on the WorldClim website (http://www. worldclim.org/), with resolution of 30" in each hexagon; and (iv) the number of ecoregions (Ecg) in each hexagon (Olson et al. 2001), which can be interpreted as a measure of environmental heterogeneity.

\section{Data Analysis}

Congruence between species richness and phylogenetic diversity was assessed using a Pearson correlation with degrees of freedom correction (Clifford et al. 1989) to remove the effect of spatial autocorrelation. This analysis was performed by the SAM 4.0 software (Rangel et al. 2006).

To identify the effect of environmental variables over diversity measures, 11 additive models were formulated based on all possible combinations among the four environmental variables, except those that combined the two energy hypotheses in the same model (PET and NPP). In addition, a twelfth model was included as a null model, containing no environmental variables and formed only by the intercept. The modeling procedure was equal for species richness and PD, and only differed for rPD by the inclusion of species richness as covariate to all its models. Spatial filters were added as mandatory covariates to all models (including the null), in order to remove the spatial autocorrelation of the residues, as suggested by Diniz-Filho et al. (2008). These filters were generated by SAM 4.0 (Rangel et al. 2006) through a Principal Coordinate Analysis, and only those filters with a spatial autocorrelation value (Moran's I) greater than 0.1 were included in the analysis to avoid the "overcorrection" of the analysis (Diniz-Filho \& Bini 2005). This way, 39 filters were added to the models, which were sufficient to remove spatial autocorrelation in all distance classes.

A model selection approach based on the Akaike information criteria (AIC) was adopted to identify those models with better fit to the data (Burnham \& Anderson 2002). This approach proposes to compare a large number of models at a single time, and identify among those models the one that is the simplest and provides the best fit to the data simultaneously (Johnson \& Omland 2004), and it usually presents robust results regardless of the autocorrelation control method used (Diniz-Filho et al. 2008). The models were selected based on the Akaike criteria for small samples (AICc), and the best models were defined based on the $\triangle \mathrm{AICc}$ values and Akaike weights $\left(\mathrm{w}_{\mathrm{i}}\right)$ as proposed by Burnham \& Anderson (2002). Models with $0<\Delta_{\mathrm{i}} \leq 2$ were considered the most plausible, while $\Delta_{\mathrm{i}}>10$ models have essentially no empirical support (Burnham \& Anderson 2002). The relative importance of the variables was determined by adding the Akaike weights of all the models in which the variable was present $(\mathrm{w}+)$. The average model parameters were obtained by weighting them by $\mathrm{w}_{\mathrm{i}}$ of the best models to obtain the best estimate of the relation between the predictor variables and response. Both regressions and calculation of AICc values were performed in program R 3.3.1 (R Core Team 2015).

\section{RESULTS}

Didelphimorphia species distribution extends from the eastern United States to southern 
Argentina and Chile, with a strong spatial structuring in Didelphimorphia species richness, with the highest values recorded in the Peruvian Andes $(\mathrm{N}=25$ species $)$ and Southeast Brazil $(\mathrm{N}=$ 19 species), and the lowest ( $\mathrm{N}=1$ species) recorded in the extreme of its distribution (Figure 1a). PD was also strongly structured in space, with a pattern of variation broadly coincident with that of species richness (Figure 1b). The correlation of the two variables was positive and highly significant, even after the spatial autocorrelation was controlled $\left(\mathrm{r}=0.982 ; \mathrm{df}_{\text {corr }}=6.01 ; \mathrm{p}_{\text {corr }}<0.001\right)$. The rPD also presented spatial structure, but its pattern was different from that observed in the other measures of diversity: the lowest values were observed mostly in mountainous regions along the tropical Andes, from Ecuador to Bolivia, in the Venezuelan Tepuis, and in the Brazilian southeast, while their highest values were recorded either in the central portion of Brazil, spreading from the Cerrado to the limits of the Caatinga and southeastern Amazonia, or in the Guiana Shield, except the Tepui region (Figure 1c).

A single model, composed of productivity, topography, and number of ecoregions, was pointed as the most plausible to explain the spatial variation of both species richness and $\mathrm{PD}\left(\mathrm{w}_{\mathrm{i}}=\right.$ 1.000 , for both variables) (Table 1). In both cases it was clearly detached from the following models $\left(\Delta_{\mathrm{i}}\right.$
$=31.40 ; \mathrm{w}_{\mathrm{i}}=0.000$ and $\Delta_{\mathrm{i}}=34.08 ; \mathrm{w}_{\mathrm{i}}=0.000$, respectively), and the null models $\left(\Delta_{\mathrm{i}}=734.60 ; \mathrm{w}_{\mathrm{i}}=\right.$ 0.000 and $\Delta_{\mathrm{i}}=752.16 ; \mathrm{w}_{\mathrm{i}}=0.000$, respectively), and was therefore the only model considered in the analysis of regression coefficients. For these two measures of diversity, the productivity and the number of ecoregions presented a positive relation, while the topography presented a negative relation. In neither case was potential evapotranspiration considered a plausible variable (Table 2).

When the effect of species richness on the PD was taken into account, the importance of the variables changed (Table 1). Two models could be considered equally plausible to describe the variation of $\mathrm{rPD}$, and both were clearly superior to the null model $\left(\Delta_{\mathrm{i}}=84.15 ; \mathrm{w}_{\mathrm{i}}=0.000\right)$. The first model consisted of potential evapotranspiration, topography, and the number of ecoregions $\left(\Delta_{\mathrm{i}}=\right.$ $\left.0.00 ; \mathrm{w}_{\mathrm{i}}=0.487\right)$, while the second model contained only potential evapotranspiration, and topography $\left(\Delta_{\mathrm{i}}=0.32 ; \mathrm{w}_{\mathrm{i}}=0.414\right)$. Potential evapotranspiration and topography presented high relative importance, while the number of ecoregions was less important, and productivity was negligible. Potential evapotranspiration was positively related to rPD whereas measures of environmental heterogeneity (topography and number of ecoregions) were negatively related to it (Table 2).

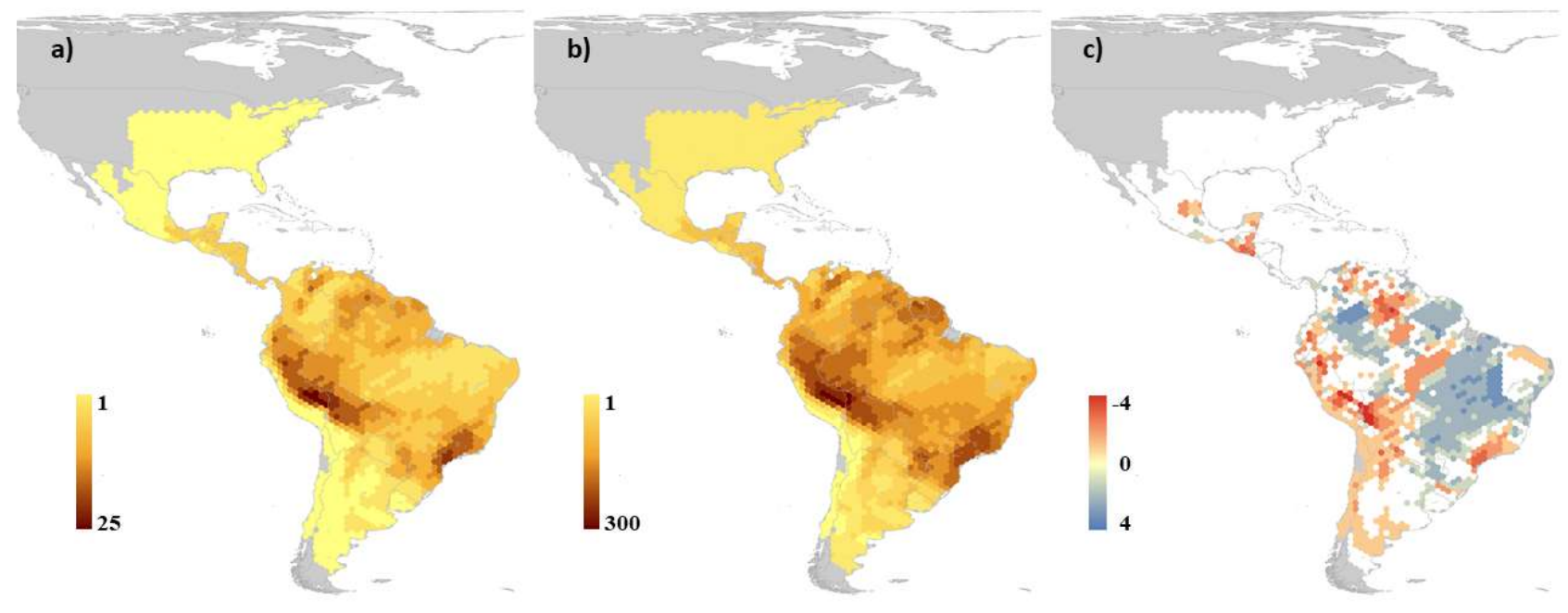

Figure 1. Distribution of observed Didelphimorphia (a) species richness, (b) phylogenetic diversity (PD), and (c) phylogenetic diversity relative to that expected from observed species richness (rPD) mapped to a $12,100 \mathrm{~km}^{2}$ resolution equal-area (Behrman) projection grid. In grey, areas without Didelphimorphia species. 
Table 1. Performance of models predicting species richness, phylogenetic diversity (PD), and relative phylogenetic diversity (rPD) of Didelphimorphia based on four environmental determinants. Most plausible models are highlighted in bold. PET = potential evapotranspiration, NPP = net primary productivity, Topo = topography, Ecg = number of ecoregions. AICc $=$ Akaike criteria for small samples, $\mathrm{K}=$ number of parameters of the model, $\mathrm{w}_{\mathrm{i}}=$ Akaike weights. All models include 39 spatial filters to account for spatial correlation, and all models of relative phylogenetic diversity include species richness as a mandatory covariate.

\begin{tabular}{|c|c|c|c|c|}
\hline Order & Models & $\triangle \mathrm{AICc}$ & $\mathbf{K}$ & $\mathbf{W}_{\mathbf{i}}$ \\
\hline \multicolumn{5}{|l|}{ Species richness } \\
\hline 1 & NPP + Topo + Ecg & 0.00 & 44 & 1.000 \\
\hline 2 & $\mathrm{NPP}+\mathrm{Ecg}$ & 31.40 & 43 & 0.000 \\
\hline 11 & Null & 735.60 & 41 & 0.000 \\
\hline \multicolumn{5}{|l|}{ PD } \\
\hline 1 & NPP + Topo + Ecg & 0.00 & 44 & 1.000 \\
\hline 2 & NPP + Topo & 34.08 & 43 & 0.000 \\
\hline 12 & Null & 752.16 & 41 & 0.000 \\
\hline \multicolumn{5}{|l|}{ rPD } \\
\hline 1 & PET + Topo + Ecg & 0.00 & 45 & 0.487 \\
\hline 2 & PET + Topo & 0.32 & 44 & 0.414 \\
\hline 3 & $\mathrm{NPP}+\mathrm{Topo}+\mathrm{Ecg}$ & 4.46 & 45 & 0.052 \\
\hline 4 & $\mathrm{NPP}+$ Topo & 4.68 & 44 & 0.047 \\
\hline 5 & Topo + Ecg & 18.75 & 44 & 0.000 \\
\hline 12 & Null & 84.15 & 42 & 0.000 \\
\hline
\end{tabular}

Table 2. Akaike weights $(\mathrm{w}+)$ and average slope estimate of the four environmental determinants calculated by models predicting species richness, phylogenetic diversity, and relative phylogenetic diversity of Didelphimorphia. PET = potential evapotranspiration, NPP = net primary productivity, Topo = topography, Ecg = Number of ecoregions.

\begin{tabular}{lcc}
\hline \multicolumn{1}{c}{ Variable } & $\mathbf{w}_{+}$ & Average slope \\
\hline Species richness & & - \\
PET & 0.000 & 0.057 \\
NPP & 1.000 & -0.002 \\
Topo & 1.000 & 0.347 \\
Ecg & 1.000 & - \\
\hline PD & & 0.702 \\
PET & 0.000 & -0.028 \\
NPP & 1.000 & 4.405 \\
Topo & 1.000 & 0.006 \\
Ecg & 1.000 & - \\
\hline PPD & & -0.007 \\
PET & 0.901 & 0.186 \\
NPP & 0.099 & \\
Topo & 1.000 & 0.539 \\
Ecg & & \\
\hline
\end{tabular}

\section{DISCUSSION}

The strong relationship between species richness and phylogenetic diversity was already expected, given the influence of species richness on the PD index (Schweiger et al. 2008), and the spatial patterns of both diversity measures coincide with those already as described for other groups in the same region, such as World's mammals (Schipper et al. 2008), amphibians (Fritz \& Rahbek 2012), birds (Voskamp et al. 2017), and Neotropical vipers (Fenker et al. 2014). The rPD in turn presented a very distinct pattern of spatial variation, with low values observed in mountainous regions in the central Andes and southeastern Brazil, as observed in other studies (Davies et al. 2007, Davies \& Buckley 2011, Fritz \& Rahbek 2012, Voskamp et al. 2017), and the highest values of rPD spreading from southeastern Amazonia to the Cerrado and Caatinga, contrary to what has been reported by almost all of these same studies, with the exception of Davies \& Buckley (2011), with which 
there is a partial congruence. Central Brazilian forests are an important part of the evolutionary history of Didelphimorphia, connecting the main blocs of South American tropical forest and acting, effectively, as a contact zone among these two biomes (Costa 2003). So, it is not surprising that the highest values of $\mathrm{rPD}$ are found around this region.

All three measures of diversity had a strong positive relation with energy, but there was a difference between the energy measures regarding their importance to diversity measures. Productivity showed a clear positive relation with species richness, as already demonstrated in other studies in the literature (Hawkins et al. 2003b, Davies et al. 2007), and consistent with the hypothesis that more energy results in more individuals and consequently more species (Currie et al. 2004, Evans et al. 2005b), and the same was observed in relation to PD. But when the species richness effect was controlled, the influence of productivity on rPD disappeared and was replaced by potential evapotranspiration, which points to a role of environmental energy in the process of diversification, possibly due an increase in speciation rates (Gillooly \& Allen 2007, Brown 2014), caused by faster mutation rates and shorter generation times (Rohde 1992). This result contrasts with those presented by other authors who neither could isolate the effects of the two energy measurements due to their collinearity (Davies et al. 2007), nor did make any distinction between energy hypotheses (Voskamp et al. 2017).

The heterogeneity variables presented more ambiguous results when compared to energy, as had been observed for birds of the world (Voskamp et al. 2017). The number of ecoregions presented strong positive relation both to species richness and $\mathrm{PD}$, while the topography contradicted what was expected by presenting a negative relation to these two measures. Although both variables are associated with the hypothesis of environmental heterogeneity, they represent its different aspects. The number of ecoregions can be interpreted as a measure of the number of habitat types in a region which, depending on the niche requirements of species, can determine the quantities of species that can coexist in mesoscale (Leibold et al. 2004, Braga et al. 2017). Topography, on its turn, is a measure of topographic hetero- geneity that is generally correlated with several measures of environmental heterogeneity, such as climatic or vegetation types (Ruggiero \& Hawkins 2008, Melo et al. 2009). Thus, it can be used to describe both physical barriers to dispersal, and climatic gradients that may result in different types of habitat (Janzen 1967, McCain 2009, Zuloaga \& Kerr 2017).

The relationship between heterogeneity and species richness has been known for several decades (Klopfer \& MacArthur 1960, August 1983) and its positive effect on PD had already been observed by Davies et al. (2007) for the world's Psittacidae. This way, the observed result between the number of ecoregions and both measures of biological diversity of Didelphimorphia is within what was expected. Similarly, the relationship between topography and species richness has been described as generally positive (Hawkins et al. 2003a, Ruggiero \& Kitzberger 2004, Davies et al. 2007), which is contrary to what we observed in this study with the Didelphimorphia. As topography is a complex variable which can be used as a proxy to several ecological or biogeographical processes, it is possible that, when controlling for the effect of the number of ecoregions on richness and $\mathrm{PD}$, topography becomes negatively related to these two measures, suggesting that Didelphimorphia is more associated with the environmental heterogeneity represented by vegetation types (number of ecoregions) than to mountain climatic gradients.

When the species richness effect over PD was removed, the number of ecoregions lost importance within the models, unlike topography, which remained as an important and negatively related variable. The negative relation between topography and rPD is already well known (Davies et al. 2007, Fritz \& Rahbek 2012, Voskamp et al. 2017), and usually is a result of some type of barrier to colonization by other lineages, or of a process of vicariance within the region (Davies \& Buckley 2011). The diversification of the small mammals fauna of the South American mountains seems to have been an event both a rapid and recent, having occurred in late Miocene (Patterson et al. 2012), and events of this type, of rapid diversification of few lineages, tend to result in low rPD values (Davies \& Buckley 2011, Fritz \& Rahbek 2012). 
Physical geography and ecological differences among habitats can shape biogeographical patterns and drive speciation in continental faunas (Giarla \& Jansa 2014). South American biogeographical history is complex, with the emergence of large mountain ranges and the repeated expansions and contractions of forests and formations open throughout the Cenozoic (Safford 1999, Patterson et al. 2012, Leite et al. 2016, Sobral-Souza \& Lima-Ribeiro 2017). Many of these events have affected the radiation of Didelphimorphia lineages, as the cyclic expansion-contraction of tropical forests (Costa 2003, Leite et al. 2016) and open areas (Giarla \& Jansa 2014), and the rise of the Andes (Patterson $e t$ al. 2012), leaving marks on their phylogenetic register. Comparing these patterns with those of other autochthonous taxa whose evolutionary history and geographic range is congruent to the Didelphimorphia could provide interesting clues about the processes that shaped the diversification of Neotropical fauna (Fritz \& Rahbek 2012).

\section{ACKNOWLEDGMENTS}

During the development of this paper MSLF was supported by post-doctoral grants from PAPD CAPES/FAPERJ (E-26/102.366/2010) and PDJ CNPq (150734/2015-8), and CEVG received productivity fellowship and grants from $\mathrm{CNPq}$ and FAPERJ. This paper was developed in the context of National Institutes for Science and Technology (INCT) in Ecology, Evolution and Biodiversity Conservation, supported by MCTIC/CNpq (proc. 465610/2014-5) and FAPEG.

\section{REFERENCES}

Astúa, D. 2015. Family Didelphidae (Opossums). In: D. E. Wilson \& R. A. Mittermeier (Eds.), Handbook of the mammals of the world. Vol. 5. Monotremes and marsupials. pp. 70-186. Barcelona: Lynx Edicions.

August, P. V. 1983. The role of habitat complexity and heterogeneity in structuring tropical mammal communities. Ecology, 64(6), 1495-1507. DOI: $10.2307 / 1937504$
Braga, C., Oliveira, J. A., \& Cerqueira, R. 2017. Metacomunidades: uma introdução aos termos e conceitos. Oecologia Australis, 21(2), 108-118. DOI: 10.4257/oeco.2017.2102.02

Brown, J. H. 2014. Why are there so many species in the tropics? Journal of Biogeography, 41(1), 8-22. DOI: $10.1111 /$ jbi.12228

Burnham, K. P., \& Anderson, D. R. 2002. Model selection and multimodel inference. 2nd ed. New York: Springer Science: p. 488.

Clifford, P., Richardson, S., \& Hémon, D. 1989. Assessing the significance of the correlation between two spatial processes. Biometrics, 45(1), 123-134. DOI: 10.2307/2532039

Costa, L. P. 2003. The historical bridge between the Amazon and the Atlantic Forest of Brazil: a study of molecular phylogeography with small mammals. Journal of Biogeography, 30(1), 7186. DOI: 10.1046/j.1365-2699.2003.00792.x

Currie, D. J. 1991. Energy and large-scale patterns of animal- and plant-species richness. The American Naturalist, 137(1), 27-49. DOI: 10.10 86/285144

Currie, D. J., Mittelbach, G. G., Cornell, H. V., Field, R., Guégan, J.-F., Hawkins, B. A., Kaufman, D. M., Kerr, J. T., Oberdorff, T., O’Brien, E., \& Turner, J. R. G. 2004. Predictions and tests of climate-based hypotheses of broad-scale variation in taxonomic richness. Ecology Letters, 7(12), 1121-1134. DOI: $10.1111 /$ j.1461-0248.20 04.00671.x

Davies, R. G., Orme, C. D. L., Webster, A. J., Jones, K. E., Blackburn, T. M., \& Gaston, K. J. 2007. Environmental predictors of global parrot (Aves: Psittaciformes) species richness and phylogenetic diversity. Global Ecology and Biogeography, 16(2), 220-233. DOI: 10.1111/j.14668238.2007.00282.x

Davies, T. J., \& Buckley, L. B. 2011. Phylogenetic diversity as a window into the evolutionary and biogeographic histories of present-day richness gradients for mammals. Philosophical Transactions of the Royal Society B: Biological Sciences, 366(1576), 2414-2425. DOI: 10.1098/rstb.2011. 0058

Diniz-Filho, J. A. F., \& Bini, L. M. 2005. Modelling geographical patterns in species richness using eigenvector-based spatial filters. Global Ecology and Biogeography, 14(2), 177-185. DOI: 10.111 
1/j.1466-822X.2005.00147.x

Diniz-Filho, J. A. F., Rangel, T. F. L. V. B., \& Bini, L. M. 2008. Model selection and information theory in geographical ecology. Global Ecology and Biogeography, 17(4), 479-488. DOI: 10.11 11/j.1466-8238.2008.00395.x

Evans, K. L., \& Gaston, K. J. 2005. Can the evolutionary-rates hypothesis explain speciesenergy relationships? Functional Ecology, 19(6), 899-915. DOI: 10.1111/j.1365-2435.2005.01046.x

Evans, K. L., Warren, P. H., \& Gaston, K. J. 2005a. Does energy availability influence classical patterns of spatial variation in exotic species richness? Global Ecology and Biogeography, 14(1), 57-65. DOI: 10.1111/j.1466-822X.2004.0 0134.x

Evans, K. L., Warren, P. H., \& Gaston, K. J. 2005b. Species-energy relationships at the macroecological scale: a review of the mechanisms. Biological Reviews, 80(1), 1-25. DOI: 10.1017/ S1464793104006517

Faith, D. P. 1992. Conservation evaluation and phylogenetic diversity. Biological Conservation, 61(1), 1-10. DOI: 10.1016/0006-3207(92)91201-3

Faurby, S., \& Svenning, J. C. 2015. A species-level phylogeny of all extant and late Quaternary extinct mammals using a novel heuristichierarchical Bayesian approach. Molecular Phylogenetics and Evolution, 84, 14-26. DOI: 10.1016/j.ympev.2014.11.001

Fenker, J., Tedeschi, L. G., Pyron, R. A., \& Nogueira, C. C. 2014. Phylogenetic diversity, habitat loss and conservation in South American pitvipers (Crotalinae: Bothrops and Bothrocophias). Diversity and Distributions, 20(10), 1108-1119. DOI: $10.1111 /$ ddi.12217

Fergnani, P. N., \& Ruggiero, A. 2017. The latitudinal diversity gradient in South American mammals revisited using a regional analysis approach: the importance of climate at extratropical latitudes and history towards the tropics. PLoS ONE, 12(9), 1-19. DOI: 10.13 71/journal.pone.0184057

Fine, P. V. A. 2015. Ecological and evolutionary drivers of geographic variation in species diversity. Annual Review of Ecology, Evolution, and Systematics, 46(1), 369-392. DOI: 10.114 6/annurev-ecolsys-112414-054102

Fritz, S. A., \& Rahbek, C. 2012. Global patterns of amphibian phylogenetic diversity. Journal of
Biogeography, 39(8), 1373-1382. DOI: 10.1111/ j.1365-2699.2012.02757.x

Giarla, T. C., \& Jansa, S. A. 2014. The role of physical geography and habitat type in shaping the biogeographical history of a recent radiation of Neotropical marsupials (Thylamys : Didelphidae). Journal of Biogeography, 41(8), 1547-1558. DOI: $10.1111 /$ jbi. 12320

Gillooly, J. F., \& Allen, A. P. 2007. Linking global patterns in biodiversity to evolutionary dynamics using Metabolic Theory. Ecology, 88(8), 1890-1894. DOI: 10.1890/06-1935.1

Hawkins, B. A. 2001. Ecology's oldest pattern? Trends in Ecology and Evolution, 16(8), 470-470. DOI: 10.1016/S0169-5347(01)02197-8

Hawkins, B. A., Field, R., Cornell, H. V., Currie, D. J. Guégan, J.-F., Kaufman, D. M., Kerr, J. T., Mittelbach, G. G., Oberdorff, T., O’Brien, E. M., Porter, E. E., \& Turner, J. R. G. 2003a. Energy, water, and broad-scale geographic patterns of species richnes. Ecology, 84(12), 3105-3117. DOI: 10.1890/03-8006

Hawkins, B. A., Porter, E. E., \& Diniz-Filho, J. A. F. 2003b. Productivity and history as predictors of the latitudinal diversity gradient of terrestrial birds. Ecology, 84(6), 1608-1623. DOI: 10.1890/ 0012-9658(2003)084[1608:PAHAPO]2.0.CO;2

IUCN. 2012. IUCN Red List of Threatened Species. Version 2012.1. Retrieved on August 10, 2013, from http://www.iucnredlist.org.

Janzen, D. H. 1967. Why mountain passes are higher in the tropics. The American Naturalist, 101(919), 233-249. DOI: 10.1086/282487

Johnson, J. B., \& Omland, K. S. 2004. Model selection in ecology and evolution. Trends in Ecology and Evolution, 19(2), 101-108. DOI: 10.1016/j.tree.2003.10.013

Kamilar, J. M., \& Guidi, L. M. 2010. The phylogenetic structure of primate communities: variation within and across continents. Journal of Biogeography, 37(5), 801-813. DOI: 10.1111/ j.1365-2699.2009.02267.x

Kaspari, M., Ward, P. S., \& Yuan, M. 2004. Energy gradients and the geographic distribution of local ant diversity. Oecologia, 140(3), 407-413. DOI: $10.1007 /$ s00442-004-1607-2

Kerr, J., \& Packer, L. 1997. Habitat heterogeneity as a determinant of mammal species richness in high-energy regions. Nature, 385(6613), 252-254. DOI: $10.1038 / 385252 \mathrm{a} 0$ 
Klopfer, P. H., \& MacArthur, R. H. 1960. Niche size and faunal diversity. The American Naturalist, 94(877), 293-300. DOI: 10.1086/282130

Leibold, M. A. 1998. Similarity and local coexistence of species in regional biotas. Evolutionary Ecology, 12(1), 95-110.

Leibold, M. A., Holyoak, M., Mouquet, N., Amarasekare, P., Chase, J. M., Hoopes, M. F., Holt, R. D., Shurin, J. B., Law, R., Tilman, D., Loreau, M., \& Gonzalez, A. 2004. The metacommunity concept: a framework for multi-scale community ecology. Ecology Letters, 7(7), 601-613. DOI: 10.1111/j.1461-0248.2004.0 0608. $\mathrm{x}$

Leibold, M. A., Economo, E. P., \& Peres-Neto, P. 2010. Metacommunity phylogenetics: separating the roles of environmental filters and historical biogeography. Ecology Letters, 13(10), 1290-1299. DOI: 10.1111/j.1461-0248.2010.015 23. $\mathrm{X}$

Leite, Y. L. R., Costa, L. P., Loss, A. C., Rocha, R. G., Batalha-Filho, H., Bastos, A. C., Quaresma, V. S., Fagundes, V., Paresque, R., Passamani, M., \& Pardini, R. 2016. Neotropical forest expansion during the last glacial period challenges refuge hypothesis. Proceedings of the National Academy of Sciences, 113(4), 1008-1013. DOI: 10.1073/pnas.1513062113

Magurran, A. E. 2004. Measuring biological diversity. Oxford: Blackwell Publishing: p. 264.

McCain, C. M. 2009. Global analysis of bird elevational diversity. Global Ecology and Biogeography, 18(3), 346-360. DOI: 10.1111/j.14 66-8238.2008.00443.x

Melo, A. S., Rangel, T. F. L. V. B., \& Diniz-Filho, J. A. F. 2009. Environmental drivers of beta-diversity patterns in New-World birds and mammals. Ecography, 32(2), 226-236. DOI: 10.1111/j.16000587.2008.05502.x

Mittelbach, G. G., Steiner, C. F., Scheiner, S. M., Gross, K. L., Reynolds, H. L., Waide, R. B., Willig, M. R., Dodson, S. I., \& Gough, L. 2001. What is the observed relationship between species richness and productivity? Ecology, 82(9), 23812396. DOI: 10.1890/0012-9658(2001)082[2381:W ITORB]2.0.CO;2

Mittelbach, G. G., Schemske, D. W., Cornell, H. V., Allen, A. P., Brown, J. M., Bush, M. B., Harrison, S. P., Hurlbert, A. H., Knowlton, N., Lessios, H. A., McCain, C. M., McCune, A. R., McDade, L. A.,
McPeek, M. A., Near, T. J., Price, T. D., Ricklefs, R. E., Roy, K., Sax, D. F., Schluter, D., Sobel, J. M., \& Turelli, M. 2007. Evolution and the latitudinal diversity gradient: speciation, extinction and biogeography. Ecology Letters, 10(4), 315-331. DOI: $10.1111 /$ j.1461-0248.2007.01020.x

Olson, D. M., Dinerstein, E., Wikramanayake, E. D., Burgess, N. D., Powell, G. V. N., Underwood, E. C., D’Amico, J. A., Itoua, I., Strand, H. E., Morrison, J. C., Loucks, C. J., Allnutt, T. F., Ricketts, T. H., Kura, Y., Lamoreux, J. F., Wettengel, W. W., Hedao, P., \& Kassem, K. R. 2001. Terrestrial ecoregions of the world : a new map of life on Earth. BioScience, 51(11), 933938. DOI: 10.1641/0006-3568(2001)051[0933:T EOTWA]2.0.CO;2

Patterson, B. D., Solari, S., \& Velazco, P. M. 2012. The role of the Andes in the divesification and biogeography of Neotropical mammals. In: B. D. Patterson \& L. P. Costa (Eds.), Bones, clones, and biomes: the history and geography of recent Neotropical mammals. pp. 351-378. Chicago: The University of Chicago Press.

Pianka, E. R. 1966. Latitudinal gradients in species diversity: a review of concepts. The American Naturalist, 100(910), 33-46. DOI: 10.1086/2823 98

R Core Team. 2015. R: a language and environment for statistical computing. Version 3.2.2. R Foundation for Statistical Computing, Vienna.

Rahbek, C., \& Graves, G. R. 2001. Multiscale assessment of patterns of avian species richness. Proceedings of the National Academy of Sciences of the United States of America, 98(8), 4534-4539. DOI: 10.1073/pnas.071034898

Rangel, T. F. L. V. B., Diniz-filho, J. A. F., \& Bini, L. M. 2006. Towards an integrated computational tool for spatial analysis in macroecology and biogeography. Global Ecology and Biogeography, 15(4), 321-327. DOI: 10.1111/j.1466-82 2x.2006.00237.x

Rohde, K. 1992. Latitudinal gradients in species diversity: the search for the primary cause. Oikos, 65(3), 514-527. DOI: 10.2307/3545569

Ruggiero, A., \& Hawkins, B. A. 2008. Why do mountains support so many species of birds? Ecography, 31(3), 306-315. DOI: 10.1111/j.200 8.0906-7590.05333.x

Ruggiero, A., \& Kitzberger, T. 2004. Environmental correlates of mammal species richness in South 
America: effects of spatial structure, taxonomy and geographic range. Ecography, 27(4), 401417. DOI: $10.1111 /$ j.0906-7590.2004.03801.x

Safford, H. D. 1999. Brazilian Páramos I. An introduction to the physical environment and vegetation of the campos de altitude. Journal of Biogeography, 26(4), 693-712. DOI: 10.1046/j.1 365-2699.1999.00313.x

Schipper, J., Chanson, J. S., Chiozza, F., Cox, N. A., Hoffmann, M., Katariya, V., Lamoreux, J., Rodrigues, A. S. L., Stuart, S. N., Temple, H. J., Baillie, J., Boitani, L., Lacher Jr., T. E., Mittermeier, R. A., Smith, A. T., Absolon, D., Aguiar, J. M., Amori, G., Bakkour, N., Baldi, R., Berridge, R. J., Bielby, J., Black, P. A., Blanc, J. J., Brooks, T. M., Burton, J. A., Butynski, T. M., Catullo, G., Chapman, R., Cokeliss, Z., Collen, B., Conroy, J., Cooke, J. G., da Fonseca, G. A. B., Derocher, A. E., Dublin, H. T., Duckworth, J. W., Emmons, L., Emslie, R. H., Festa-Bianchet, M., Foster, M., Foster, S., Garshelis, D. L., Gates, C., Gimenez-Dixon, M., Gonzalez, S., GonzalezMaya, J. F., Good, T. C., Hammerson, G., Hammond, P. S., Happold, D., Happold, M., Hare, J., Harris, R. B., Hawkins, C. E., Haywood, M., Heaney, L. R., Hedges, S., Helgen, K. M., Hilton-Taylor, C., Hussain, S. A., Ishii, N., Jefferson, T. A., Jenkins, R. K. B., Johnston, C. H., Keith, M., Kingdon, J., Knox, D. H., Kovacs, K. M., Langhammer, P., Leus, K., Lewison, R., Lichtenstein, G., Lowry, L. F., Macavoy, Z., Mace, G. M., Mallon, D. P., Masi, M., McKnight, M. W., Medellín, R. A., Medici, P., Mills, G., Moehlman, P. D., Molur, S., Mora, A., Nowell, K., Oates, J. F., Olech, W., Oliver, W. R. L., Oprea, M., Patterson, B. D., Perrin, W. F., Polidoro, B. A., Pollock, C., Powel, A., Protas, Y., Racey, P., Ragle, J., Ramani, P., Rathbun, G., Reeves, R. R., Reilly, S. B., Reynolds, J. E., Rondinini, C., Rosell-Ambal, R. G., Rulli, M., Rylands, A. B., Savini, S., Schank, C. J., Sechrest, W., Self-Sullivan, C., Shoemaker, A., Sillero-Zubiri, C., De Silva, N., Smith, D. E., Srinivasulu, C., Stephenson, P. J., van Strien, N., Talukdar, B. K., Taylor, B. L., Timmins, R., Tirira, D. G., Tognelli, M. F., Tsytsulina, K., Veiga, L. M., Vié, J.-C., Williamson, E. A., Wyatt, S. A., Xie, Y., Young, B. E. 2008. The status of the world's land and marine mammals: diversity, threat, and knowledge. Science, 322(5899), 225-230. DOI: 10.1126/science. 1165115
Schweiger, O., Klotz, S., Durka, W., \& Kühn, I. 2008. A comparative test of phylogenetic diversity indices. Oecologia, 157(3), 485-495. DOI: 10.10 07/s00442-008-1082-2

Sobral-Souza, T., \& Lima-Ribeiro, M. S. 2017. De volta ao passado: revisitando a história biogeo.gráfica das florestas neotropicais úmidas. Oecologia Australis, 21(2), 93-107. DOI: 10.425 7/oeco.2017.2102.01

Terribile, L. C., Diniz-Filho, J. A. F., Rodríguez, M. Á., \& Rangel, T. F. L. V. B. 2009. Richness patterns, species distributions and the principle of extreme deconstruction. Global Ecology and Biogeography, 18(2), 123-136. DOI: 10.1111/j.14 66-8238.2008.00440.x

Voskamp, A., Baker, D. J., Stephens, P. A., Valdes, P. J., \& Willis, S. G. 2017. Global patterns in the divergence between phylogenetic diversity and species richness in terrestrial birds. Journal of Biogeography, 44(4), 709-721. DOI: 10.1111/jbi. 12916

Webb, C. O. 2000. Exploring the phylogenetic structure of ecological communities: an example for rain forest trees. The American Naturalist, 156(2), 145-155. DOI: 10.1086/303378

Webb, C. O., Ackerly, D. D., McPeek, M. A., \& Donoghue, M. J. 2002. Phylogenies and community ecology. Annual Review of Ecology and Systematics, 33(1), 475-505. DOI: 10.1146/annu rev.ecolsys.33.010802.150448

Weiblen, G. D., Webb, C. O., Novotny, V., Basset, Y., \& Miller, S. E. 2006. Phylogenetic dispersion of host use in a tropical insect herbivore community. Ecology, 87 (7 Suppl), S62-S75.

Willig, M. R., Kaufman, D. M., \& Stevens, R. D. 2003. Latitudinal gradients of biodiversity: pattern, process, scale, and synthesis. Annual Review of Ecology, Evolution, and Systematics, 34(1), 273-309. DOI: 10.1146/annurev.ecolsys.3 4.012103 .144032

Zuloaga, J., \& Kerr, J. T. 2017. Over the top: do thermal barriers along elevation gradients limit biotic similarity? Ecography, 40(4), 478-486. DOI: $10.1111 /$ ecog.01764

Submitted: 29 October 2017

Accepted: 05 February 2018 Associate Editor: Marcelo M. Weber 